\title{
Can a central pattern generator produce multiple motor patterns? Modeling scratch rhythms in turtle
}

Abigail Snyder*, Jonathan Rubin

From Twenty First Annual Computational Neuroscience Meeting: CNS*2012

Decatur, GA, USA. 21-26 July 2012

A central pattern generator (CPG) is a population of neurons producing rhythmic or repetitive behavior (i.e. scratching, walking, masticating) without requiring rhythmic input to the population. Turtles are observed to produce several rhythmic motor patterns in response to stimuli, in particular rostral scratch, pocket scratch, caudal scratch, and forward swim (see Figure 1A) [1], [2]. The rostral scratch and pocket scratch rhythms are created through the activity of three motoneurons: Hip Extensor (HE), Knee Extensor (KE) and Hip Flexor
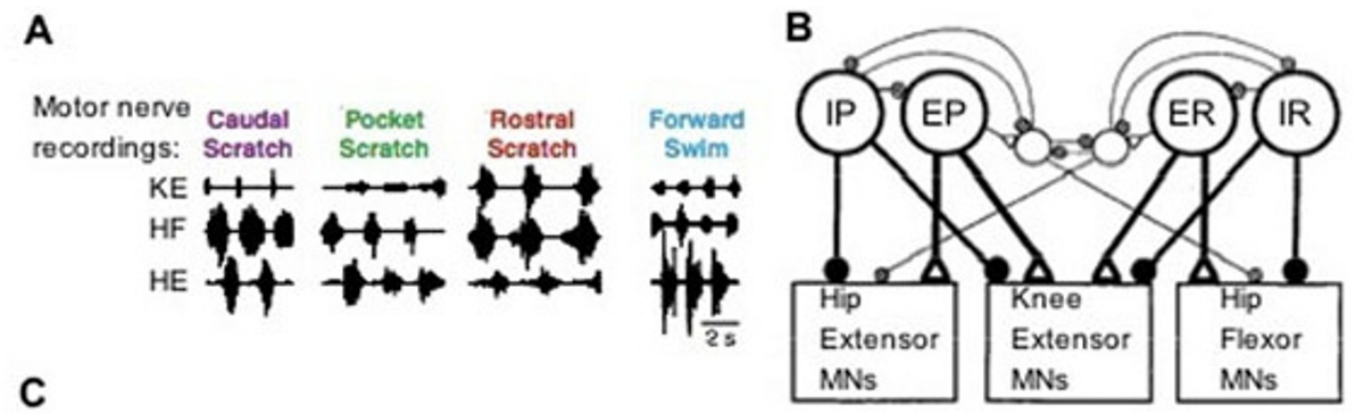

C
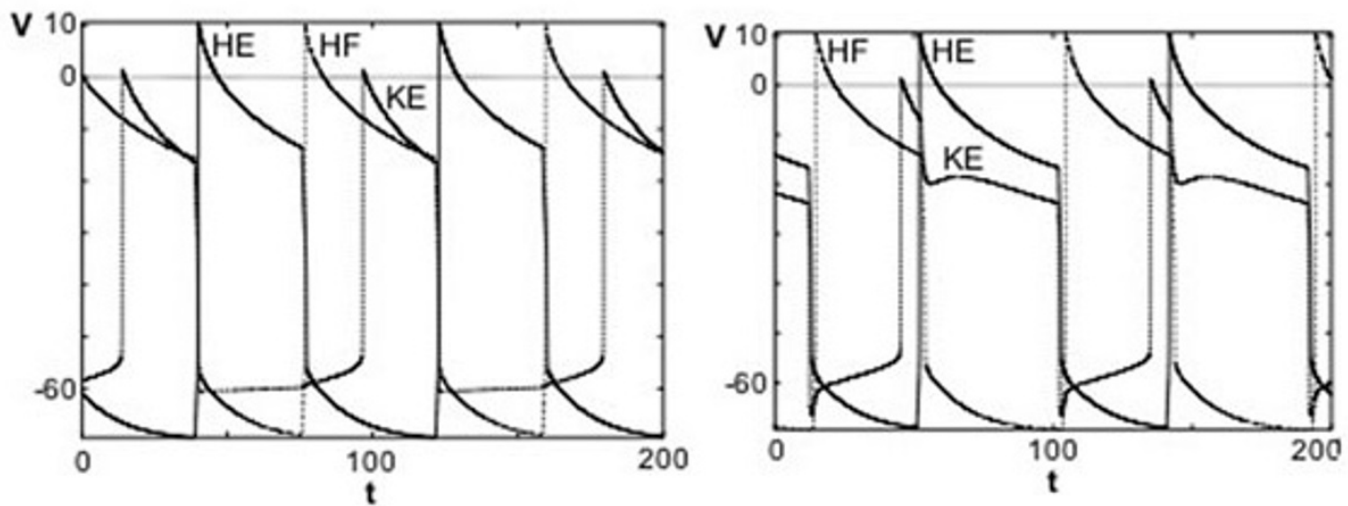

Figure 1 A. Example recordings of fictive scratching and fictive swimming [2]; B. The proposed CPG [1]; C. Results of simulation for Rostral (left) and Pocket (right) scratch.

\footnotetext{
*Correspondence: acs73@pitt.edu

Department of Mathematics, University of Pittsburgh, Pittsburgh, PA 15213,
} USA

\section{() Biomed Central}

(c) 2012 Snyder and Rubin; licensee BioMed Central Ltd. This is an Open Access article distributed under the terms of the Creative Commons Attribution License (http://creativecommons.org/licenses/by/2.0), which permits unrestricted use, distribution, and reproduction in any medium, provided the original work is properly cited. 
(HF). A CPG (see Figure 1B) for rostral scratch and caudal scratch has been proposed, featuring overlapping populations of spinal neurons such that each spinal neuron projects to each motoneuron to produce both scratch rhythms via changing inputs [1]. We implement the CPG as a system of relaxation oscillators. The system successfully reproduces the desired rhythms (see Figure 1C). We also consider a dynamical systems approach to determine the mechanisms underlying rhythm generation, seeking the minimal network necessary to produce both rhythms. Additionally, we numerically explore the role of model parameters and present sufficient conditions on model parameters to produce both rhythms.

Published: 16 July 2012

\section{References}

1. Berkowitz A, Stein PSG: Activity of descending propriospinal axons in the turtle hindlimb enlargement during two forms of fictive scratching: phase analyses. J Neurosci 1994, 14(8):5105-5119.

2. Berkowitz A: Physiology and morphology of shared and specialized spinal interneurons for locomotion and scratching. J Neurophysiol 2008, 99:2887-901

doi:10.1186/1471-2202-13-S1-P52

Cite this article as: Snyder and Rubin: Can a central pattern generator produce multiple motor patterns? Modeling scratch rhythms in turtle. BMC Neuroscience 2012 13(Suppl 1):P52.

\section{Submit your next manuscript to BioMed Central} and take full advantage of:

- Convenient online submission

- Thorough peer review

- No space constraints or color figure charges

- Immediate publication on acceptance

- Inclusion in PubMed, CAS, Scopus and Google Scholar

- Research which is freely available for redistribution

Submit your manuscript at www.biomedcentral.com/submit 